Southern Illinois University Carbondale

OpenSIUC

\title{
Reducing the Costs of Meeting Regional Water Demand Through Risk-based Transfer Agreements
}

Gregory W. Characklis

University of North Carolina at Chapel Hill

Reed N. Palmer

Hazen \& Sawyer

Follow this and additional works at: http://opensiuc.lib.siu.edu/ucowrconfs_2007

Abstracts of the presentations given on Wednesday, 25 July 2007, in Session 13 of the UCOWR Conference.

\section{Recommended Citation}

Characklis, Gregory W. and Palmer, Reed N., "Reducing the Costs of Meeting Regional Water Demand Through Risk-based Transfer Agreements" (2007). 2007. Paper 25.

http://opensiuc.lib.siu.edu/ucowrconfs_2007/25 


\title{
Reducing the Costs of Meeting Regional Water Demand Through Risk-based Transfer Agreements
}

Gregory W. Characklis, University of North Carolina at Chapel Hill, Chapel Hill, NC; Reed N. Palmer, Hazen \& Sawyer, Raleigh, NC

\begin{abstract}
Transfers of treated water among inter-connected utilities is becoming more common as the cost of developing new supplies grows, and transfer agreements require well developed rules describing when and how much water will be transferred. The nature of the decision rules governing an agreement must also be coordinated with respect to the treatment and conveyance capacity required to execute the transfers. This study explores different combinations of infrastructure and agreement type that define three different transfer programs, describing the frequency and volume of transfers associated with each, as well as its costs. The agreements are described in terms of the type of decision rule employed: Take-or-Pay, with the timing and quantity of transfers fixed; Days of Supply Remaining (DSR), which uses a static hydrologic indicator to trigger transfers; and Riskof-Failure, a probability-based decision rule that involves consideration of both supply and demand. The analysis is applied to the Research Triangle area of North Carolina (USA), a rapidly growing area that is beginning to approach the practical limits of water resource development. The Risk-of-Failure agreement reduces the average volume of transfers by over $80 \%$ compared to a Take-or-Pay agreement and by roughly half relative to the DSR agreement, leading to significant cost reductions. A utility's willingness to accept something less than guaranteed access to a specified quantity of water (i.e. an interruption) also has a significant impact on cost. Interruptions do not necessarily lead to lower reliability, but rather to the purchasing utility acquiring more water during off-peak periods when the seller has excess treatment capacity available, and the lowest cost guaranteed agreement is $40 \%$ to $50 \%$ more expensive than the lowest cost interruptible contract.
\end{abstract}

Author Contact Information:

Gregory Characklis

charack@email.unc.edu 